\title{
Pulsatility of the umbilical cord in full-term natural childbirths
}

\author{
Thamires Ribeiro Marques Mendonça ${ }^{a}$ \\ Regina Célia Sales Santos ${ }^{a, b}$ \\ Pollyana Campos Limab \\ Maria Gabriella Silva Araujo ${ }^{\mathrm{b}, \mathrm{c}}$ \\ Maria Elisângela Torres Lima Sanches ${ }^{a}$ \\ Jovânia Marques Lima e Silva ${ }^{a, b}$
}

\section{How to cite this article:} Mendonç TRM, Santos RCS, Lima PC, Araujo MGS, Sanches METL, Silva JML. Pulsatility of the umbilical cord in full-term natural childbirths. Rev Gaúcha Enferm. 2021;42:e20200241 doi: https://doi.org/10.1590/19831447.2021.20200241
'Universidade Federal de Alagoas (UFAL), Escola de Enfermagem. Maceió, Alagoas, Brasil.

- Universidade Federal de Alagoas (UFAL), Programa de Pós-graduação em Enfermagem. Maceió, Alagoas, Brasil.

Universidade Federal de Alagoas (UFAL), Programa de Pós-graduação da Rede Nordeste de Biotecnologia. Maceíó, Alagoas, Brasil.

\section{ABSTRACT}

Objective: Measure umbilical cord pulsatility time and evaluate correlation/association with maternal and neonatal characteristics. Method: Cross-sectional study, with 76 binomials, carried out in 2017, in a maternity hospital in Alagoas. Analysis with Pearson or Spearman correlation test and Mann-Whitney or Kruskal-Wallis test.

Results: Sixty-two parturients and their newborns participated of the research. The women had a gestational age $\geq 37$ weeks, natural cephalic birth, without distortions. The newborns had average weight of $3326.29 \mathrm{~g}$, mostly male. The umbilical cord pulsatility time was 285.48 s. There is a correlation between umbilical cord pulsatility time and placental delivery time $(p<0.001)$. Other correlations/associations were not significant.

Conclusion: It suggested using a correlation between pulsatility time and placental delivery time in clinical decision making for good practices in childbirth assistance.

Keywords: Umbilical cord. Natural childbirth. Maternal-child nursing.

\section{RESUMO}

Objetivo: Mensurar tempo de pulsatilidade do cordão umbilical e avaliar correlação/associação com característica maternas e neonatais.

Método: Estudo transversal, com 76 binômios, realizado no ano de 2017, em maternidade de Alagoas. Análise com teste de correlação de Pearson ou Spearman e teste de Mann-Whitney ou Kruskal-Wallis.

Resultados: Sessenta e duas parturientes e seus recém-nascidos participaram da pesquisa. As mulheres tinham idade gestacional $\geq 37$ semanas, parto normal cefálico, sem distorcias. Os recém-nascidos tinham peso médio de 3326,29g, maioria do sexo masculino. 0 tempo de pulsatilidade do cordão umbilical foi 285,48s. Há correlação entre tempo de pulsatilidade do cordão umbilical e tempo de dequitação da placenta $(p<0,001)$. Demais correlações/associações não foram significativas.

Conclusão: Sugere-se o uso correlação entre tempo de pulsatilidade e tempo de dequitação da placenta na tomada de decisão clínica para boas práticas na assistência ao parto.

Palavras-chave: Cordão umbilical. Parto normal. Enfermagem materno-infantil.

\section{RESUMEN}

Objetivo: Medir tiempo de pulsatilidad del cordón umbilical y evaluar la correlación/asociación con las características maternas y neonatales.

Método: Estudio transversal, con 76 pares, realizado en 2017, en maternidad en Alagoas. Análisis con la prueba de correlación de Pearson o Spearman y la prueba de Mann-Whitney o Kruskal-Wallis.

Resultados: Sesenta y dos mujeres en trabajo de parto y sus recién nacidos participaron. Las mujeres tenían edad gestacional $\geq 37$ semanas, parto cefálico normal, sin distorsiones. Los recién nacidos tenían peso promedio de 3326.29g, la mayoría de ellos varones. Tiempo de pulsatilidad del cordón umbilical fue de 285.48s. Había correlación entre el tiempo de pulsatilidad del cordón umbilical y el momento del parto placentario $(p<0,001)$. Otras correlaciones/asociaciones no fueron significativas.

Conclusión: Sugiere una correlación entre el tiempo de pulsatilidad y el tiempo de parto placentario para las buenas prácticas en la atención del parto

Palabras clave: Cordón umbilical. Parto normal. Enfermería maternoinfantil. 


\section{IINTRODUCTION}

The placenta, a transitory organ that has the same genetic composition as the fetus, plays a main role in supplying the fetus and, in particular, the fetal brain, with oxygen and nutrients. It is structurally adapted for this, having a large surface area for exchanges and a thin interhematological membrane, which separates the maternal and fetal circulations. Its surfaces are: the basal plate that is next to the maternal endometrium and the chorionic plate that faces the fetus and to which the umbilical cord is attached ${ }^{(1)}$.

The umbilical cord has a length that can vary from 35 to $100 \mathrm{~cm}$ and the factors that determine its length are largely unknown ${ }^{(2)}$. It contains two arteries that carry the little oxygenated blood towards the placenta and a vein through which the oxygen-rich blood flows to the fetus ${ }^{(3)}$.

After birth, the blood flow from the umbilical cord remains for some time, which favors the transfusion of residual blood from the placenta to the fetus. One way to ensure that this transfusion is completed is the late clamping of the umbilical cord(4).

Thus, the delayed clamping time of the umbilical cord results in a placental blood transfusion for the newborn, which facilitates the transition to extra-uterine life ${ }^{(5)}$. In term neonates, late clamping of the umbilical cord increases hemoglobin levels at birth and improves iron stores in the first months of life, which can have a favorable effect on developmental results ${ }^{(6)}$.

It is known that factors such as the time of clamping of the umbilical cord, uterine contractions, the NB's breathing and the force of gravity can influence the blood volume transferred from the placenta to the fetus after birth ${ }^{(7)}$. As the umbilical cord pulsatility (UCP) is directly related to a significant reduction in the blood flow that runs through it, the time elapsed between the complete delivery of the newborn and the total cessation of pulse in the umbilical cord without external interruption, called UCP time could be altered by maternal and neonatal characteristics.

However, it was still necessary to know about the quantification of UCP time and how it can be affected by other maternal and neonatal characteristics (including fetal attachments) in order to use this knowledge to improve the quality of care provided and support safely the clinic decision-making.

This study aimed to measure the time of the umbilical cord pulsatility and to evaluate its association and correlation with maternal and neonatal characteristics.

\section{METHOD}

\section{Type of Study}

This was an observational, descriptive cross-sectional study with a quantitative approach.

\section{Field}

The study was carried out in a hospital located in the municipality of União dos Palmares, Alagoas, Brazil. The unit has a maternity hospital that attends parturients of habitual risk and their newborns and was selected as the research scenario for following the Good Obstetric Practices, including late clamping of the umbilical cord.

\section{Selection criteria}

Participated in the study single gestation parturients, with gestational age greater than or equal to 37 weeks, who evolved to normal cephalic birth without distortions, and their newborns.

Parturients with pre-eclampsia/eclampsia were excluded from the study; Parturients who used antihypertensives and/ or anticoagulants; Parturients with fetuses without vitality or in fetal distress; Parturients who presented any clinical or obstetric complications that justified the performance of cesarean delivery or the need for immediate interruption of the umbilical flow; Parturients with fetuses who had congenital disabilities or intrauterine delay.

Newborns with hypoxia, positive Rh factor with the possibility of Rh incompatibility were also excluded; and newborns with Apgar $<7$ in the first minute.

\section{Sample}

The calculated sample was based on the study by Sinavszki et al. $(2013)^{(8)}$, composed by 76 binomials (parturient and newborn) considering a standard deviation of 147 seconds, with maximum error of estimate of $33 \%$ and significance level of $5 \%$.

The sampling process was non-random and intentional for parturient women from any region, who were referred or admitted to the service spontaneously. Recruitment occurred after admission of the parturient to the service when they were invited to participate in the study. 


\section{Data collection}

Data collection took place from July to October 2017. The births were attended by obstetric nurses, physicians, and midwives, and each parturient was entitled to a companion during labor and delivery. Data collection was performed by a researcher who did not provide birth assistance. At the time of birth, the professional who assisted the delivery placed the newborn in skin-to-skin contact with the mother until the time of clamping, which occurred only after checking the total cessation of the umbilical cord pulse. The umbilical cord pulsatility time was measured using the palpation method, with the support of a stopwatch performed by a single person. After clamping the umbilical cord, the professionals performed the first care for the newborn, while measuring the placental delivery time.

The data were recorded in a form developed by the main researcher regarding the variables of maternal and neonatal characteristics, in addition to information related to fetal attachments. In relation to parturient women, the following variables were evaluated: age, number of pregnancies, number of deliveries, number of abortions, gestational age, immediate postpartum body mass index (BMI), uterine fundal height (UFH), systolic blood pressure and diastolic. In relation to the newborn, the variables were evaluated: weight, length, respiratory rate, heart rate, capurro, Apgar index 1st minute, Apgar index 5th minute, head circumference and chest circumference. About the variables related to fetal attachments were evaluated: umbilical cord pulsatility time, umbilical cord circumference, placental delivery time. The height of the newborn position after the expulsion period was also evaluated, for this, it was considered the measure from the midpoint of the vaginal opening to the newborn's back during skin-to-skin contact.

\section{Data analysis}

The quantitative analysis was performed by a team member who had not participated in the previous stages of the study, with the data stored in the database of the statistical package SPSS (Statistical Package for Social Sciences) Version 21.0.0.0. For descriptive analysis, means, percentages and standard deviation were calculated. For the inferential analysis, the Kolmogorov-Smirnov test was used to verify the normal distribution of variables. For correlations of maternal variables, fetal attachments and neonatal variables, Pearson and Spearman's correlation coefficient was used. The Kruskal-Wallis $(H)$ and Mann-Whitney $U$ test was used to establish the association between fetal attachments and umbilical cord pulsatility. The research adopted a significance level of $5 \%(p<0.05)$. The data were presented through tables for better interpretation of the results and discussed according to the literature.

\section{Ethical aspects}

The study was approved by the Research Ethics Committee (CEP) of the Universidade Federal de Alagoas with the statement number 2.172.226 and CAAE number 66845717.0 .0000 .5013 , following the precepts of Resolution $466 / 12$ and 510/16 of the National Health Council about research with human beings.

The parturients who agreed to participate in the research signed the Terms of Free and Informed Consent (ICF) and the adolescent parturients signed the Term of Free and Informed Assent (IAF), in addition to having ICF's signed by their parents/legal guardians. Anonymity was guaranteed and the withdrawal of consent was guaranteed at any stage of the study.

\section{RESULTS}

In the study were included 76 binomials (parturient and $\mathrm{NB})$, however among the participants there were losses that totaled 14 binomials. Among these, seven parturients clinically evolved to cesarean delivery, the administration of oxytocin during delivery was performed in three parturients, two parturients were transferred to another maternity, there was the occurrence of eclampsia in one parturient, and one participant expressed the desire to leave the study at the time of delivery, resulting in 62 binomials (Figure 1).

The time of the umbilical cord pulsatility (UCP) showed mean of 285.48 seconds ( \pm 296.14 ), which corresponds to 4.75 minutes. It presented a great variation from times of only 38 seconds to 1020 seconds. Some correlations were made with variables related to fetal attachments, presented in the table 1.

In relation to the umbilical cord circumference, which presented an average of $4.09( \pm 0.88)$ in this study, it showed no correlation with the UCP time. Regarding the mean placental delivery time, which was 743.43 ( \pm 597.01$)$ corresponding to 12.39 minutes, it showed a positive and moderate correlation with the UCP time $(p<0.001)$. The difference in means between the UCP time and the placental delivery time corresponded to 457.95 seconds (7.63 minutes), an increase of $160 \%$ in relation to the UCP. In relation to the placenta weight, which had an average of $592.02( \pm 128.31)$ and did not show any correlation with the UCP time. 
The umbilical cords were evaluated for the presence of nodes or circulars in 11 (17.7\%) of the binomials, and in these, the UCP time corresponded to 293.81 ( \pm 48.00$)$ seconds. There was no significant difference in the UCP times

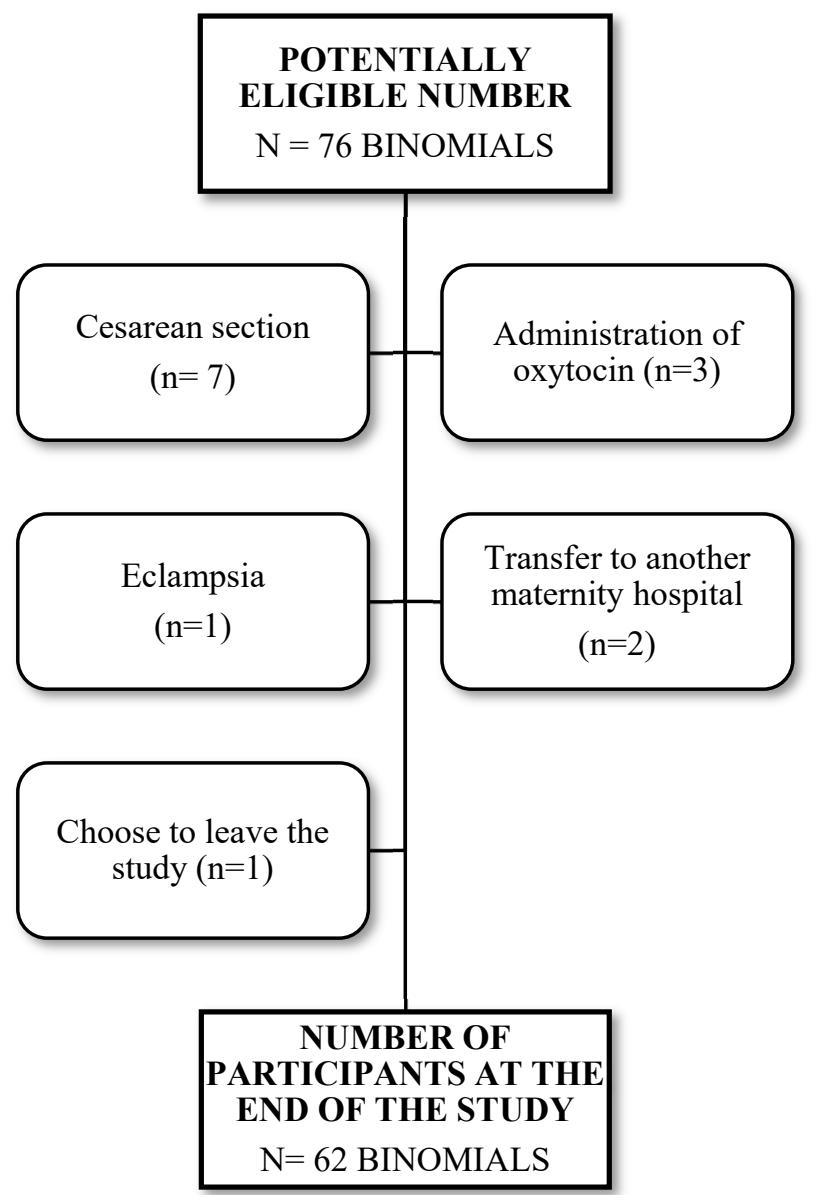

Figure 1 - Flowchart of losses of study participants Source: Research data, 2017. between the binomials that presented cord circulars with the time of those that did not ( $p=0.261$ ) (Table 2$)$.

The placental location, which was assessed using the last ultrasound record of the third trimester of pregnancy, showed values of means that differed from each other, despite this difference not being statistically significant $(p=0.441)$. The mean UCP time was longer in women with anterior placental location (264.74 \pm 53.48 seconds), while the lowest mean time to pulsatility occurred in fundal locations (198.60 \pm 99.35 seconds). Only one parturient had a placenta located laterally (Table 2).

As for the placental maturity, analyzed in ultrasound records of the third trimester of pregnancy, a progressive reduction in UCP was observed. Placentas with degree 0 of maturity had an average UCP time of 458.92 ( \pm 104.93$)$ seconds, while the placentas of grade III showed a UCP time of 163.50 ( \pm 99.80$)$ seconds. Despite this reduction in mean UCP time, there was no significant association between the degree of placental maturity and the umbilical cord pulsatility time $(p=0.189)$ (Table 2).

Regarding obstetric variables, women who participated in the study had an average of two pregnancies. From the 62 parturients, 28 (45.2\%) were in the first pregnancy, 21 (33.9\%) in the second pregnancy, and the other 13 (20.9\%) participants had already had more than two pregnancies. As for the number of deliveries, most women (51.6\%) were primiparous, 21 parturients (33.9\%) were secondary, while the remaining 9 parturients (14.5\%) were in the third or more deliveries. The average number of deliveries in the entire sample was $0.83( \pm 1.33)$. As for cases of previous abortions, 53 parturients (85.5\%) had not had any abortion, while 6 (9.7\%) women had a historic of 1 episode, 3 (4.8\%) parturients had two abortions. The mean of abortion was $0.19( \pm 0.55)$. None

Table 1 - Correlation of the umbilical cord pulsatility time with the other variables related to fetal attachments, União dos Palmares, AL, Brazil, 2017

\begin{tabular}{lcccc} 
Variables of Fetal Attachments & Mean $( \pm \mathbf{s d})$ & Min-Max & $\mathbf{R}$ & p-value \\
UCP time* (seconds) & $285.48(296.14)$ & $38-1020$ & - & - \\
Cord circumference $(\mathrm{cm})$ & $4.09( \pm 0.88)$ & $3.0-7.0$ & 0.107 & 0.407 \\
Placental delivery time (seconds) & $743.43( \pm 597.01)$ & $175-3455$ & $0.605^{\mathrm{a}}$ & 0.000 \\
Placenta weight (grams) & $592.02( \pm 128.31)$ & $330-885$ & 0.171 & 0.184 \\
\hline
\end{tabular}

Source: Research data, 2017

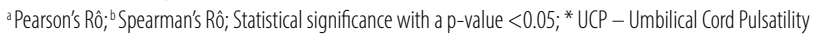


of these variables showed a significant correlation in relation to the umbilical cord pulsatility time (Table 3).

The age of parturient women participating in the study ranged from 13 years to 39 years with a mean age of 21.54 $( \pm 5.33)$ years. The parturients had a mean of $39.72( \pm 1.31)$ weeks of gestation and the uterine fundal height varying between 21 and $40 \mathrm{~cm}$, maintaining a mean of $32.13( \pm 3.44)$ $\mathrm{cm}$. They also had a mean body mass index of $25.25( \pm 3.35)$ with most women (62.9\%) maintaining one of these classification indexes: from 18.5 to 24.9 (35.5\%) and from 25.0 to 29.9 (27.4\%). Neither the gestational age nor the body mass index correlated with the umbilical cord pulsatility time (Table 3).

Regarding blood pressure in the expulsive period, it can be seen that women showed systolic blood pressure with a mean of $127.24( \pm 12.77)$, diastolic blood pressure with a mean of $76.12( \pm 10.96)$ and a mean difference between these two pressures at $50.94( \pm 10.81)$. No significant correlation was observed between maternal blood pressure variables and umbilical cord pulsatility time.

Regarding the habits of women during pregnancy, only two (3.2\%) claimed to be smokers, while the rest denied this habit. The UCP time did not show any significant difference between the groups of women who smoked and did not smoke during pregnancy, with a mean of $376( \pm 313.50)$ seconds and $287.04( \pm 44.37)$ respectively $(p=0.858)$. Regarding the habit of drinking alcoholic beverages during pregnancy, only 3 (4.8\%) women said they had it, the other parturients denied this practice. Women with a habit of drinking alcoholic beverages showed mean UCP times of $77.66( \pm 13.67)$ seconds and the group that did not have this habit of 304.97 $( \pm 45.73)$ seconds with non-significant differences $(p=0.198)$.

Table 2 - Association between umbilical cord pulsatility time with variables related to fetal attachments, União dos Palmares, AL, Brazil, 2017

\begin{tabular}{lcccc} 
Variables of & & Umbilical cord pulsatility time & \\
Fetal Attachments & Mean $( \pm \mathbf{s d})$ & SEM & Min-Max & p-value \\
\cline { 2 - 4 } Cord Circular & & & \\
Yes & $293.81( \pm 48.00)$ & 159.19 & $57-565$ & $0.261^{c}$ \\
No & $299.20( \pm 52.52)$ & 328.00 & $40-1020$ &
\end{tabular}

Placental location

\begin{tabular}{|c|c|c|c|c|}
\hline Anterior & $264.74( \pm 53.48)$ & 297.76 & $40-1020$ & \multirow{4}{*}{$0.441^{\mathrm{d}}$} \\
\hline Posterior & $255.45( \pm 54.55)$ & 255.90 & $38-893$ & \\
\hline Fundal & $198.60( \pm 99.35)$ & 222.15 & $60-573$ & \\
\hline Lateral & 953.00 & - & - & \\
\hline \multicolumn{5}{|c|}{ cental Maturity } \\
\hline Grade 0 & $458.92( \pm 104.93)$ & 392.63 & $42-1005$ & \multirow{4}{*}{$0.189^{d}$} \\
\hline Grade I & $261.11( \pm 61.59)$ & 253.98 & $49-1020$ & \\
\hline Grade II & $21537(+5421)$ & 21684 & $40-720$ & \\
\hline Grade III & $163.50( \pm 99.80)$ & 199.61 & $45-460$ & \\
\hline
\end{tabular}


Mendonça TRM, Santos RCS, Lima PC, Araujo MGS, Sanches METL, Silva JML

Table 3 - Correlation of maternal variables with the umbilical cord pulsatility time, União dos Palmares, AL, Brazil, 2017

\begin{tabular}{|c|c|c|c|c|}
\hline Maternal Variables & Mean (sd) & (Min-Max) & $\mathbf{R}$ & p value \\
\hline Age (years) & $21.54( \pm 5.33)$ & $13-39$ & $0.009^{b}$ & 0.948 \\
\hline Pregnancies & $2.03( \pm 1.60)$ & $1-9$ & $-0.072^{b}$ & 0.577 \\
\hline Births & $0.83( \pm 1.33)$ & $0-6$ & $-0.127^{b}$ & 0.325 \\
\hline Abortions & $0.19( \pm 0.55)$ & $0-2$ & $0.027^{b}$ & 0.834 \\
\hline Gestational Age (weeks) & $39.72( \pm .31)$ & $37-42.42$ & $-0.177^{a}$ & 0.168 \\
\hline $\mathrm{UFH}^{*}(\mathrm{~cm})$ & $32.13( \pm 3.44)$ & $21-40$ & $-0.047^{\mathrm{a}}$ & 0.717 \\
\hline BMIt in the immediate postpartum & $25.25( \pm 3.35)$ & $19.2-32.8$ & $-0.143^{\mathrm{a}}$ & 0.366 \\
\hline $\mathrm{SBP} \neq(\mathrm{mmHg})$ & $127.24( \pm 12.77)$ & $97-154$ & $0.130^{\mathrm{b}}$ & 0.336 \\
\hline $\mathrm{DBP} \S(\mathrm{mmHg})$ & $76.12( \pm 10.96)$ & $50-91$ & $0.155^{b}$ & 0.248 \\
\hline $\mathrm{SBP} \neq-\mathrm{DBP} \S(\mathrm{mmHg})$ & $50.94( \pm 10.81)$ & $30-80$ & $0.041^{\mathrm{a}}$ & 0.761 \\
\hline
\end{tabular}

Source: Research data, 2017.

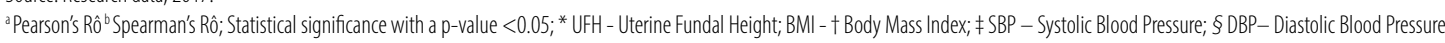

The newborn sample consisted by 23 (37.1\%) females and 39 (62.9\%) males. UCP time means showed no significant difference in groups by gender, with values of 219.39 $( \pm 51.16)$ seconds and $324.46( \pm 51.07)$ seconds respectively $(p=0.180)$. The birth weight of newborns that ranged from 2340 to 4200 grams and the average weight of 3326.29 ( \pm 400.4$)$ grams. Presented a mean length of $50.52( \pm 2.37)$ $\mathrm{cm}$, a mean head circumference of $33.83( \pm 1.17) \mathrm{cm}$, and a mean thoracic perimeter of $33.90( \pm 1.94) \mathrm{cm}$. None of these variables of anthropometric measurements of newborns showed a significant correlation with the umbilical cord pulsatility time (Table 4).

Regarding the newborn's vitality at birth, the mean respiratory rate was 66.48 ( \pm 15.97 ), while the mean heart rate was 139.41 ( \pm 15.31$)$. In relation to the mean Apgar score in the 1st minute, the newborns had values of $8.75( \pm 0.53)$, evolving to a mean Apgar score in the 5th minute of 9.09 $( \pm 0.29)$. About Somatic Capurro, newborns showed mean values of 279.61 ( \pm 12.01). All variables related to the newborn's vitality and somatic capurro did not show significant correlation with the umbilical cord pulsatility time (Table 4).
The presence of meconium during delivery was not associated with the mean UCP time $(p=0.946)$. The five newborns (8.1\%) who had meconium at delivery recorded a mean UCP time of $289.43( \pm 40.37)$ seconds, while the 57 (91.9\%) newborns who did not presented, registered a mean UCP time of 240.40 ( \pm 82.29) seconds.

\section{DISCUSSION}

The measurement of the umbilical cord pulsatility time was 285 seconds ( 4 minutes and 45 seconds). Smaller umbilical cord pulsatility times were found in a study conducted in Florence, Italy with 102 women that found a value of 213 seconds, which corresponds to 3 minutes and 33 seconds ${ }^{(9)}$.

The circumference measurement of the umbilical cords did not show any correlation with the UCP. In a study that evaluated umbilical cord measurements using ultrasound during pregnancy, found that there was no correlation between fetal anthropometric measurements and umbilical cord circumference, despite the umbilical cord circumference being significantly smaller until the 30th gestational week, significantly increased in following weeks until delivery ${ }^{(10)}$. 
Table 4 - Correlation of neonatal variables with umbilical cord pulsatility time, União dos Palmares, AL, Brazil, 2017

\begin{tabular}{|c|c|c|c|c|}
\hline Neonatal Variables & Mean ( $\pm s d)$ & Mín. - Max & $\mathbf{R}$ & p value \\
\hline Weight (grams) & $3326.29( \pm 400.4)$ & $2340-4200$ & $-0.006^{\mathrm{a}}$ & 0.965 \\
\hline Length (cm) & $50.52( \pm 2.37)$ & $45-56$ & $-0.008^{b}$ & 0.948 \\
\hline Head circumference $(\mathrm{cm})$ & $33.83( \pm 1.17)$ & $31-37$ & $-0.038^{b}$ & 0.731 \\
\hline Thoracic Perimeter (cm) & $33.90( \pm 1.94)$ & $30-38$ & $0.046^{a}$ & 0.723 \\
\hline Respiratory Rate (ripm*) & $66.48( \pm 15.97)$ & $35-100$ & $-0.013^{a}$ & 0.920 \\
\hline Heart Rate (bpm†) & $139.41( \pm 15.31)$ & $88-172$ & $0.173^{b}$ & 0.179 \\
\hline Somatic Capurro & $279.61( \pm 12.01)$ & $259-348$ & $-0.054^{\mathrm{a}}$ & 0.675 \\
\hline Apgar score 1 min. & $8.75( \pm 0.53)$ & $7-9$ & $0.076^{b}$ & 0.560 \\
\hline Apgar score 5 min. & $9.09( \pm 0.29)$ & $9-10$ & $0.119^{b}$ & 0.357 \\
\hline
\end{tabular}

Source: Research data, 2017

a Pearson's Rô; ${ }^{\mathrm{b}}$ Spearman's Rô; Statistical significance with a p-value $<0.05$; $^{*}$ ripm - respiratory incursions per minute; $†$ bpm - beats per minute.

The presence of circulars in the umbilical cord did not show any significant association with the UCP, in addition to the absence of real nodes. Likewise, in a study that evaluated the macroscopic characteristics of the umbilical cord in high-risk pregnancies and neonatal repercussions, the frequency of true nodes was only 1 case in 256 cases analyzed $^{(11)}$, demonstrating to be low the frequency of circulars/ true cord nodes.

The placental delivery time showed a positive and moderate correlation with UCP. A shorter duration of UCP was related to values that were also shorter in the delivery time. In cases of longer pulsatility durations, longer discharge times were also recorded. This may be related to the great connection of these two fetal attachments, because after the blood flow interruption that occurs after the umbilical cord pulsatility session much of the blood that filled the placenta will have drained from the placental bed to the fetus, thus facilitating the detachment of the placenta that culminates in complete delivery.

The time relationship between the mean duration of the UCP and the mean time to the placental delivery corresponded to an increase of $160 \%$. It is inferred that after the end of the UCP, a time corresponding to $160 \%$ of the pulsatility duration would be necessary for the placenta to exit. This can be especially useful for professionals who assist women during childbirth labor. Knowing about the time increase that exists between the end of the umbilical cord pulsatility and the placental delivery can guide the decision to adopt an expectant conduct, or the adoption of active conduct through controlled umbilical cord traction only after the end of the waiting time period (increment).

The placenta weight did not correlate with UCP time. However, in a study in southern Brazil, which identified factors related to the quality of umbilical cord and placental blood samples, concluded that the greater the placental weight, the greater the volume of cord blood and the placenta itself ${ }^{(12)}$. Placental weight also had a positive relationship with cord length ${ }^{(2)}$.

In research performed in Tokyo, Japan (2), it was noted that the anterior location of the placenta was related to elongated length of the umbilical cord. However, in this study, there was no association between the UCP and the placental location or its maturity, both identified by ultrasound.

There was no correlation between the UCP, and the variables related to the parturient, including maternal age, gestational age, previous pregnancies, previous births and abortions, uterine fundal height, body mass index and blood pressure. In the same way, it happened about the habit of smoking or drinking alcohol during pregnancy, the UCP did not show any significant association with any of these habits. 
Regarding neonatal characteristics, no correlation was found between UCP and variables related to the newborn's vitality, anthropometric measures, or maturity, including weight and length, head and thoracic perimeter, respiratory and cardiac frequency, somatic capurro and Apgar score in the 1st and 5th minute, in addition to the presence of meconium. However, in a comparative study that evaluated pulsatility organized in two groups according to the longest or shortest duration, it also found no relationship with neonatal characteristics, except for birth weight, which showed significant association and UCP. They found that newborns with longer pulsatility duration weighed more than those with shorter pulsatility duration ${ }^{(9)}$.

\section{a CONCLUSION}

The mean of the umbilical cord pulsatility time in 4 minutes and 45 seconds. It was found a positive and moderate correlation between placental delivery time and umbilical cord pulsatility time. Difference between these two times can assist health professionals who assist delivery to guide the conducts of placental delivery active or expectant. Maternal and neonatal variables did not correlate with the cord pulsatility time.

The study in question presented as a limitation the sample size, since there were losses of binomial throughout the data collection. In view of the data found, it is expected that this study will support new research about the umbilical cord pulsatility with larger samples of binomials so that it can improve the correlations/associations between the maternal and neonatal variables.

\section{REFERENCES}

1. Burton GJ, Fowden AL. The placenta: a multifaceted, transient organ. Phil Trans R Soc B. 2015;370(1663):20140066. doi: https://doi.org/10.1098/ rstb.2014.0066
2. Ryo E, Seto HKM, Morita M, Yatsuki K. Correlation between umbilical cord length and gross fetal movement as counted by a fetal movement acceleration measurement recorder. Eur J Obstet Gynecol Reprod Biol X. 2019;1:e100003. doi: https://doi.org/10.1016/j.eurox.2019.100003

3. Rezende J, Montenegro CAB. Obstetrícia fundamental. 13. ed. Rio de Janeiro: Guanabara Koogan; 2017.

4. Katheria A, Poeltler D, Durham J, Steen J, Rico W, Arnell K, et al. Neonatal resuscitation with an intact cord: a randomized clinical trial. J Pediatr. 2016;178:75-80.e3. doi: https://doi.org/10.1016/j.jpeds.2016.07.053

5. McDonald SJ, Middleton P, Dowswell T, Morris PS. Effect of timing of umbilical cord clamping of term infants on maternal and neonatal outcomes. Cochrane Database Syst Rev. 2013;7:CD004074. doi: https://doi.org/10.1002/14651858. CD004074.pub3

6. Committee on Obstetric Practice (US). Committee Opinion No. 684: Delayed Umbilical Cord Clamping After Birth. Obstet Gynecol. 2017;129(1):e5-e10. doi: https://doi.org/10.1097/AOG.0000000000001860

7. Ministério da Saúde (BR). Manual prático para implementação da Rede Cegonha. Braślia, DF: Ministério da Saúde; 2011 [cited 2020 Jun 02]. Available from: http://www.saude.ba.gov.br/wp-content/uploads/2017/09/MANUAL_ PRATICO_MS_IMPLEMENTACAI_REDE_CEGONHA.pdf

8. Sinavszki M, Sosa N, Silvera F, Díaz Rossello JL. Clampeo tardío de cordón umbilical: saturación de oxígeno en recién nacidos. Rev Bol Ped. 2013 [cited 2020 Jun 10];52(1):28-34. Available from: http://www.scielo.org.bo/scielo. php?script=sci_arttext\&pid=S1024-06752013000100009\&lng=es\%20 ISSN\%201024-0675

9. Di Tommaso M, Carotenutoa B, Seravallia V, Malossoa ERM, Pinzautia S, Torricellib $\mathrm{M}$, et al. Evaluation of umbilical cord pulsatility after vaginal delivery in singleton pregnancies at term. Eur J Obstet Gynecol Reprod Biol. 2019;236:947 doi: https://doi.org/10.1016/j.ejogrb.2019.03.008

10. Rostamzadeh S, Kalantari M, Shahriari M, Shakiba M. Sonographic measurement of the umbilical cord and its vessels and their relation with fetal anthropometric measurements. Iran J Radiol. 2015;12(3):e12230. doi: https://doi.org/10.5812/ iranjradiol.12230v2

11. Salge AKM, Reis MR, Siqueira KM, Castral TC, Guimarães JV, Castro ECC. Association between the macroscopic characteristics of the umbilical cord, highrisk pregnancy and neonatal repercussions. Rev Esc Enferm USP. 2017;5:e03294. doi: https://doi.org/10.1590/S1980-220X2017006303294

12. Lopes LA, Bernardino E, Crozeta K, Guimarães PRB. Good practices in collecting umbilical cord and placental blood. Rev Latino-Am Enfermagem. 2016;24:e2770. doi: https://doi.org/10.1590/1518-8345.0781.2770 


\section{- Authorship contribution:}

Conceptualization: Regina Célia Sales Santos e Thamires Ribeiro Marques Mendonça.

Data curation: Regina Célia Sales Santos e Maria Gabriella Silva Araujo.

Formal analysis: Regina Célia Sales Santos e Maria Gabriella Silva Araujo.

Investigation: Thamires Ribeiro Marques Mendonça. Methodology: Regina Célia Sales Santos e Thamires Ribeiro Marques Mendonça.

Project administration: Regina Célia Sales Santos e Thamires Ribeiro Marques Mendonça.

Resources: Thamires Ribeiro Marques Mendonça. Software: Maria Gabriella Silva Araujo e Pollyana Campos Lima.

Supervision: Regina Célia Sales Santos .

Visualization: Maria Elisângela Torres Lima Sanches e Jovânia Marques Lima e Silva.

Writing-original draft: Regina Célia Sales Santos,

Thamires Ribeiro Marques Mendonça e Pollyana

Campos Lima.

Writing-review \& editing: Regina Célia Sales Santos, Thamires Ribeiro Marques Mendonça, Pollyana Campos Lima, Maria Gabriella Silva Araujo e Maria Elisângela Torres Lima Sanches e Jovânia Marques Lima e Silva.

\section{- Corresponding author:}

Regina Célia Sales Santos

E-mail: reginasales@eenf.ufal.br

Associate editor:

Jéssica Machado Teles 